\title{
Early Adolescent Alcohol Abuse in Rural Northern Michigan
}

\author{
Paul D. Sarvela, Ph.D. \\ E. J. McClendon, Ed.D.
}

\begin{abstract}
Data concerning several alcohol abuse behaviors were collected from 181 middle school students in Michigan's Upper Peninsula during May, 1982. The findings suggest that alcohol misuse in this region increases significantly with age, and appears to be at rates well above national averages. Examination of gender differences also reveals results which differ from national trends. This paper examines the general alcoholrelated abusive behaviors found in this rural youth population, and provides some recommendations for both mental health education program development and therapeutic services.
\end{abstract}

\section{INTRODUCTION}

Alcohol abuse is endemic in American society today, contributing to a number of psychological and physiological disorders, ranging from alcoholinduced toxic psychoses to the physical destruction of the nervous system. In addition, alcohol is related to 40 to $60 \%$ of all traffic fatalities involving 15 to 24 year olds, the leading cause of death among young people in the United States today (Small, 1982).

Although the distinction between alcohol abuse (or misuse) and social (nonabusive) drinking is difficult to establish, Donovan and Jessor (1978) have argued that an adolescent alcohol misuser could be defined as any student who reported drunkenness at least six times in the past year, or experienced a number of negative consequences due to drinking. Some examples of negative consequences of drinking include: trouble with

The authors are affiliated with the Department of Health Education. College of Education, Southern Illinois University. Carbondale. and Program in Health Education. School of Education. Depart ment of Health Behavior and Health Education, School of Public Health. The University of Michi. gan. Ann Arbor

The authors wish to thank the anonymous reviewers for their helpful comments on an earlier draft of this manuscript. This paper was presented at the annual meeting of the Association for the Advancement of Health Education. Las Vegas, 1987. 
teachers because of drinking, driving after drinking, and trouble with police after drinking. Using that classification system, Donovan and Jessor found that $17.2 \%$ of their sample (10th and 12th graders), $(\mathrm{N}=4,918)$ were abstainers, $51.7 \%$ were alcohol users, and $31.2 \%$ were alcohol misusers. With regard to early adolescent alcohol abuse rates, Rachal, Maisto, Guess and Hubbard (1982), using 1974 data, determined that heavier drinkers made up $4.3 \%$ of their sample of 13 year olds $(\underline{N}=3,468)$.

The differentiation between problem drinking and the use of alcohol without apparent psychosocial or physical problems is extremely important. Donovan and Jessor recently reported (1983) that "problem drinking appears to indicate greater involvement in drug use than does the use of an illicit drug, marijuana" (p. 543). Their application of the Guttman Scalogram method strongly suggested (coefficient of reproducibility $=.967$ ) that abusive drinking should be added to the sequence of drug and alcohol use first proposed by Kandel and Faust (1975) which describes the stages of youth involvement with drugs. (Kandel and Faust's stages consisted of:

1. use of beer and wine;

2. use of hard liquor and cigarettes;

3. marijuana use;

4. the use of "harder" drugs.)

Donovan and Jessor suggest additions to the scale, arguing that the stages of drug involvement fall under the following sequence:

1. no use of drugs or alcohol;

2. no problem drinking with no use of other drugs;

3. marijuana and alcohol use;

4. problem drinking and use of marijuana;

5. use of pills, problem drinking and marijuana;

6. the use of hard drugs, pills, marijuana and abusive drinking.

Rachal et al.'s (1982) report based on the same data further confirmed these findings, since their analysis suggested that alcohol misusers used marijuana at much higher frequencies than did abstainers or nonabusive alcohol users.

It is important to study youth abusive drinking patterns, because adolescent abusive drinking has been linked to several behavioral and sociologic problems. Braucht (1982), in a review of the psychosocial literature concerning adolescent alcohol abuse, argued that compared to nonproblem drinkers, adolescent problem drinkers are more likely to:

1. feel more disagreement between parental and peer expectations:

2. be more influenced by peers than parents; 
3. experience less parental disapproval of drinking practices;

4. have more peers who model problem drinking for them;

5. experience more peer approval of their drinking behavior;

6. have parents who are less involved with them and their lives;

7. have parents who are heavier drinkers themselves;

8. have parents who are less positive or affectionate toward them.

Four of the above conclusions are related to the powerful effects of peer pressure on behavior. The effects of the peer group on alcohol and other drug use is well documented in the literature (cf., Andrews \& Kandel, 1979; Huba \& Bentler, 1980; Jessor \& Jessor, 1977; Levine and Kozak, 1979; Sarvela \& McClendon, 1983a; and Sarvela, Takeshita, \& McClendon, 1986). Inadequate parenting as a cause of alcohol misuse make up the other four observations, which is supported by the research of Levine and Kozak (1979) and Zucker (1979).

Despite alcohol's tremendous impact on American life today, few studies have examined early adolescent substance abuse behavioral patterns. In addition, relatively few studies have addressed the problems of rural area youth, and those few studies have focused on high school populations (e.g., Napier, Carter, \& Pratt, 1981; Tolone \& Dermott, 1975). Research concerning rural and small town drug abuse is important because fully one-third of all Americans reside in these regions (NIDA, 1981). More importantly, there appear to be major differences between urban and rural drug abuse patterns. For example, Globetti, Alsikafi, and Morse (1978) found that rural youth drink less frequently than urban adolescents, but in a much more abusive manner. The purpose of this study was to assess the extent to which alcohol-related abusive behavior occurred in a rural, middle school population. For purposes of this study, we will suggest that alcohol misuse or abuse has occurred when subjects report any one of the following problems: alcohol induced illness behavior, intoxication or, feelings of guilt after consuming alcohol.

\section{METHOD}

Data were collected in a small town (population 10,000) in Michigan's Upper Peninsula during May, 1982. The population density of the county surveyed is approximately 25 people per square mile. This compares to a population density of Wayne county (Detroit) of 3,863 people per square mile (population density figures calculated from 1980 US Census data). Given the National Institute on Drug Abuse's (1981) definition of rura] as being any geographic region with a population under 25,000 people outside of a Standard Metropolitan Statistical Area (SMSA), the population studied can be classified as rural. Traditional rural employment is found in the region (e.g., farming and logging) and it is noteworthy that the county studied considered itself the "Dairy Capital" of the Upper Peninsula. In addition to traditional rural employment opportunities, there are several paper mills operating in the region. The unemployment rate in the county surveyed at the time of the study was $16.0 \%$, while the total 1981 unemployment rate in Michigan's Upper Peninsula was 13.3\% (Michigan Employment Security Commission, 1982). 
The subjects were sixth, seventh and eighth grade students in the local middle school. A total of 181 students were sampled, representing $34.94 \%$ of the population being studied. Although it cannot be argued that these students are representative of rural America's youth, it is possible that they are representative of this region, and perhaps of the rural Northern Midwest.

The data collection instrument was pilot tested with 496 sixth, seventh and eighth grade subjects to test for readability and to gain a general understanding of drug use trends in the rural early adolescent population. Appropriate changes were made after the pilot study, such as the rewording of certain items, deletion of poor questions, and the addition of items (not included in the earlier survey) which were considered important after examining the data provided by the pilot test. Instrument reliability and validity data have been reported in Sarvela and McClendon (1983a) and Sarvela, Takeshita, and McClendon, (1986).

Those questions assessing general abusive drinking practices were patterned after a questionnaire used in a study conducted in Manitoba (Holloway, 1964) designed to evaluate high school student alcohol use behavior. Alcohol-induced illness behavior was ex. amined by asking "Have you ever been sick from drinking too much?" Prevalence of intoxication behavior in this population was measured by asking, "Have you ever been drunk?" Finally, an estimate of a negative consequence of drinking (guilt) was obtained by asking, "Do you ever feel guilty afterward about drinking?" Possible responses for all of the above questions were: "yes," "no" and, "I don't drink."

The survey was administered by the principal investigator of the research project, who instructed the students how to answer the questionnaire, and remained in the classrooms throughout the administration of the survey. Total anonymity was emphasized. The students were not permitted to put their names on the questionnaire or answer sheets, which were machine scored by an optical scanner.

\section{RESULTS}

The data suggest that a number of abusive alcohol-related behaviors are present in this population. The overall population analysis revealed that $22.8 \%$ of the sample indicated having been sick from drinking; $35.6 \%$ reported being drunk at least once; and $20.2 \%$ said they have felt guilty after drinking.

Reported alcohol-induced illness was also examined using grade leve! as a moderating variable. As expected, the data suggested that as grade level increases the prevalence of experiencing an illness after drinking increases significantly $[\mathrm{x} 2(\underline{\mathrm{df}} 4)=19.427, \mathrm{p}<.01]$.

Alcohol-induced illness was then analyzed using sex as the moderating factor. Interestingly, the results did not suggest a significant difference between the number of males and females who reported alcoholinduced sickness, [ $\mathrm{x} 2(\underline{\mathrm{d} f} 2)=1.2438, \mathrm{p}=\mathrm{ns}]$ ]. The data concerning alcohol: induced illness rates are presented in Table 1.

Reported intoxication by grade level was analyzed next. As with the results concerning reported alcohol-induced illness, there was a significant increase in subject-reported intoxication as he or she advanced in age, $[\mathrm{x} 2(\mathrm{df} 4)=23.031, \mathrm{p}<.01]$. Reported intoxication was then assessed to examine gender differences. Surprisingly, as with illness behavior, no significant differences were found $[\mathrm{x} 2(\underline{\mathrm{df}} 2)=0.83455, \mathrm{p}=\mathrm{ns}]$ between male and female responses. These findings appear in Table 2. 


\section{Table 1}

Reported Alcohol-Induced Dlness

(Expressed in Percentages)

\begin{tabular}{|c|c|c|c|c|}
\hline & $N$ & Yes & No & Abstain \\
\hline Total Sample & 180 & 22.8 & 38.9 & 38.3 \\
\hline \multicolumn{5}{|l|}{ Grade Lerel: } \\
\hline Sixth Grade & 89 & 14.6 & 32.6 & 52.8 \\
\hline Seventh Grade & 43 & 23.3 & 51.2 & 25.6 \\
\hline Eighth Grade & 48 & 37.5 & 39.6 & 22.9 \\
\hline \multicolumn{5}{|l|}{ Sex $x^{* *}$} \\
\hline Male & 84 & 21.4 & 42.9 & 35.7 \\
\hline Female & 95 & 24.2 & 34.7 & 41.1 \\
\hline
\end{tabular}

Table 2

Reported Intoxication

(Expressed in Percentages)

\begin{tabular}{|c|c|c|c|c|}
\hline & $N$ & Yes & No & Abstain \\
\hline Total Sample & 180 & 35.6 & 30.6 & 33.9 \\
\hline $\begin{array}{l}\text { Grade Level* } \\
\text { Sixth Grade } \\
\text { Seventh Grade } \\
\text { Eighth Grade }\end{array}$ & $\begin{array}{l}89 \\
43 \\
48\end{array}$ & $\begin{array}{l}21.3 \\
37.2 \\
60.4\end{array}$ & $\begin{array}{l}33.7 \\
37.2 \\
18.8\end{array}$ & $\begin{array}{l}44.9 \\
25.6 \\
20.8\end{array}$ \\
\hline $\begin{array}{l}\text { Sex: } \\
\text { Male } \\
\text { Female }\end{array}$ & $\begin{array}{l}84 \\
95\end{array}$ & $\begin{array}{l}38.1 \\
32.6\end{array}$ & $\begin{array}{l}31.0 \\
30.5\end{array}$ & $\begin{array}{l}31.0 \\
36.8\end{array}$ \\
\hline
\end{tabular}

The final set of analyses examined the impact of guilt as a consequence of alcohol use. Consistent with the other constructs studied, the number of respondents expressing guilt after drinking increased significantly with age, $[\mathrm{x} 2(\underline{\mathrm{df}} 4)=12.916, \mathrm{p}<.01]$. Interestingly, when using sex as the moderating variable with this item, females reported significantly higher rates of postdrinking guilt $[\mathrm{x} 2(\mathrm{df} 2)=8.8884, \mathrm{p}<.01]$ than did males. 
Table 3 presents data concerning the prevalence of alcohol-use related guilt in this sample.

\section{DISCUSSION}

The data indicate that this population is highly prone to abusive drinking. More importantly, the rates appear to be much higher than national averages. While Donovan and Jessor (1978) found that five percent of the seventh grade boys and four percent of the seventh grade girls in their sample were classified as problem drinkers. $20.2 \%$ of our total sample report guilt feelings after drinking, $22.8 \%$ indicate that they have been sick after drinking and $35.6 \%$ report that they have been drunk at least one time. Although Donovan and Jessor use different definitions of problem drinking than have been used in this study, it seems reasonable to argue that the rates of alcohol abuse in Michigan's Upper Peninsula are probably higher than national averages.

The steady increase in reported abusive behavior as age advances is an expected finding. These results corroborate with other studies examining rural adolescent substance use and abuse (see for example: Kirk, 1979: McIntosh, Nyberg, Fitch, Wilson \& Staggs, 1976; Napier, Carter \& Pratt, 1981; Sarvela \& McClendon, 1983a, 1983b; Sarvela, Takeshita, \& McClendon, 1986; Tolone \& Dermott, 1975). Although data suggesting that abusive behavior increases with age is not specific to this sample, the high percentages of students reporting such behavior is noticeably

Table 3

Reported Alcohol-Related Guilt (Expressed in Percentages)

\begin{tabular}{|c|c|c|c|c|}
\hline & $N$ & Yes & No & Abstain \\
\hline Total Sample & 180 & 20.2 & 37.1 & 42.7 \\
\hline \multicolumn{5}{|l|}{ Grade Level* } \\
\hline Sixth Grade & 88 & 13.6 & 30.7 & 55.7 \\
\hline Seventh Grade & 42 & 26.2 & 40.5 & 33.3 \\
\hline Eighth Grade & 48 & 27.1 & 45.8 & 27.1 \\
\hline \multicolumn{5}{|l|}{ Sex** } \\
\hline Male & 82 & 14.6 & 48.8 & 36.6 \\
\hline Female & 95 & 24.2 & 27.4 & 48.8 \\
\hline
\end{tabular}


unique. By comparing these data with those of national studies, it is evident that this population has a much higher prevalence rate of alcohol misuse than their peers from other regions. For example, as mentioned earlier, Donovan and Jessor (1978) report that only 5\% of the boys and $4 \%$ of the girls surveyed could be classified as misusers in their sample. In the sixth grade of this study, $21.3 \%$ of the sample report being drunk, which is about four times the rate shown by the seventh graders in the national study. More importantly, by the eighth grade, fully $60 \%$ of the sample report to have been drunk at least once. This finding is an explicit warning to rural upper Great Lakes region therapists and educators-this age group must not be ignored when prevention programming and therapeutic services are planned.

Using gender as a moderating variable for the analysis produced results that were equally surprising, again contradicting major national studies. The present study's data strongly suggest that the significant differences in alcohol consumption rates characteristically present between early adolescent male and female problem drinkers are no longer present in rural Northern Michigan populations. These patterns have not been reported in national studies. For example, Braucht, in his review of several national surveys indicated that males consistently reported higher frequencies of abusive behavior than did females, at a ratio of three male alcohol misusers to every two female alcohol misusers (1982).

Of special interest is the finding that females indicated significantly higher rates of guilt feelings than males concerning their drinking behavior. This phenomenon has been discussed in the middle-aged female alcohol abuse literature (e.g., Beckman, 1975; Gomberg, 1975) but has not been reported with early adolescent populations. These data may indicate that females need more health education courses or counseling focusing on male/female differential expectations in our society. Males might also profit from this form of education, since they would gain a better understanding of the stressful societal expectations of females.

These results have interesting implications when interpreted within the rural context. For example, although little work has been done in the area of rural youth drunk driving, these findings better help interpret the recent report that fully two-thirds of all US 1985 motor vehicle deaths occurred in rural areas (National Safety Council, 1986). With 60\% of the present study's eighth grade sample reporting that they have been intoxicated at least once, it is clear that community mental health education specialists must design and implement drunk driving programs focused on middle school/junior high school age groups.

There are implications from the developmental psychology perspective as well. It may be that the high rates of alcohol abuse reported in this study are a function of the adolescent "need to belong" to the peer group. Given the high positive correlations between peer and personal drug use 
that have been previously reported concerning this sample fSarvela \& McClendon, 1983a), it is quite possible that the reported alcohol abuse rates are directly related to peer use of alcohol. With regard to the gender findings, the results may suggest that differential maturation rates between males and females regarding the onset of use and abuse of alcohol are no longer present. These data are further reinforced by the recent national studies of Johnston, O'Malley, and Bachman, who indicate that cigarette smoking is actually higher among females than male adolescents today (1985). Clearly, the data support the conclusion that differential abusive drinking patterns among rural male and female adolescents have diminished.

This study points to a number of issues which should be addressed by those involved in alcohol use/abuse program development and implementation in rural community mental health settings. Of major concern to the investigators were the extremely high prevalence rates of alcohol misuse in this sample. These data suggest that there is a strong need for alcohol education to begin no later than the sixth grade, for it is clear that by this time, heavy alcohol use has already begun for some students.

With respect to the rural health therapeutic setting, the extremely high alcohol misuse prevalence rates suggest that screening for potential alcohol or other drug abuse problems is advised when the client has reached early adolescence. Problems referred to clinicians regarding poor motivation or other behavioral disorders might be linked to some form of chemical dependency. The initial consultation should probe for potential drug abuse problems which might be associated with, or causally linked to, the actual psychopathology to be treated.

The reported prevalence rates of abusive alcohol behavior are also of concern because they may signal an abnormally high rate of marijuana consumption in this population. Since Donovan and Jessor's (1983) work places alcohol misuse at a more advanced stage of substance usage than earlier theorized, marijuana use may actually be higher than has been reported for this region.

In summary, the results of this study suggest that there is an extremely high prevalence rate of alcohol misuse among early adolescents in Northern Michigan. The rates appear to be higher than national averages. and are indicative of a number of drug-related problems. Health education alcohol use prevention programs should be developed to address these problems, and be implemented no later than the sixth grade. In addition, both educators and therapists should be made aware of the gender specific behavioral expectations present in this region, and modify their programs and therapeutic strategies to address this problem accordingly.

As is so often the case, this study raises as many or more questions than it answers. Interesting questions for future research are: whether or not these findings are applicable to urban regions; how peer pressure is linked to abusive drinking behavior; how these findings compare to 
older rural adolescent populations; and how powerful an indicator abusive drinking is of other illicit behaviors in rural America.

\section{REFERENCES}

Andrews, E. H., \& Kandel. D. B. (1979). Attitude and behavior: A specification of the contingent consistency hypothesis. American Sociological Review, 44. 298-310.

Beckman. L. J. 11975 ). Women alcoholics: A review of social and psychological studies. Journal of Studies on Alcohol, 36, 797-824.

Braucht. G. (1982). Problem drinking among adolescents: A review and analysis of the psychosocial research. Alcohol and health monograph 4: Special population issues IDHHS Pub \# ADM 82-1193). Washington. DC: U. S. Government Printing Office,

Donovan. J. E.. \& Jessor. R. (1978). Adolescent problem drinking: Psychosocial correlates in a na tional sample study. Journal of Studies on Alcohol, 39, 1506-1524.

Donovan. J. E., \& Jessor R. (1983). Problem drinking and the dimension of involvement with drugs: A Guttman scalogram analysis of adolescent drug use. American Journal of Public Health. 73. $543-552$.

Globetti. G.. Alsikafi, M. \& Morse. R. (1978). High school students and the use of alcohol in a rural community: A research note. Journal of Drug Issues. 8. 435-441.

Gomberg. E. S. 11975 . Women and alcohol: State of the knowledge wday. Paper presented at the National Council on Alcoholism Forum. Milwaukee.

Holloway. R. (1964). Student drinking: A study of Manitoba high school students behaviors. attituaes and knouledge with respect to alcohol. Alcohol Education Service. Winnipeg.

Huba, G. J.. \& Bentler. P. M. (1980). The role of peer and adult models for drug taking at different stages in adolescence. The Journal of Youth and Adolescence. 9, 449-465.

Jessor R. \& Jessor S. L. 1977). Problem behavior and psychosocial development. New York: Academic Press.

Johnston. L. D., OMalley, P. M., \& Bachman, J. G. (1985). Use of licit and illicit drugs by America's high school students, 1975-1984. (DHHS Publication \# ADM 85-1394). Washington, DC: U. S. Government Printing Office.

handel, D. B., \& Faust. R. (1975). Sequences and stages in patterns of adolescent drug use. Archices of General Psychiairy 32. 923-932.

Kirk. R. S. (19791. Drug use among rural youth. In G. M. Breschner \& A. S. Friedman (Eds.), Youth drug abuse. New York: Lexington Books.

Levine, E. M., \& Kozak. C. (1979). Drug and alcohol use. delinquency and vandalism among upper middle class pre and postadolescents. The Journal of Youth and Adolescence. 8. 91-101.

McIntosh, Wm.. Nyberg, K. L., Fitch, S. D. Wilson. J. B. \& Staggs, F. M. 11979). Age and drug use by rural and urban adolescents. Journal of Drug Education. 9. 129-143.

Michigan Emoloyment Security Commission. (1982). Research and statistics. Labor Market Analyst Section.

Napier, T. L.. Carter. T. J. \& Pratt, M. C. (1981). Correlates of alcohol and marijuana use among hign school students. Rural Sociology, 46, 319-332.

National Institute on Drug Abuse (1981). Treatment research report: Drug abuse in rural A merica DHHS Pub \# ADM 81-1050). Washington. DC: U.S. Government Printing Office.

National Safety Council (1986). Accident facts. Chicago, IL: National Safety Council.

Rachal. J. V.. Maisto, S. A., Guess, L. L.. \& Hubbard, R. L. (1982). Alcohol use among youth. Alco hol health monograph 1: Alcohol consumption and related problems (DHHS Pub $\#$ ADM 82-1190\%. Washington, DC: U.S. Government Printing Office.

Sarvela. P. D. \& McClendon, E. J. (1983a). Correlates of early adolescent peer and personal substance use in rural Northern Michigan. The Journal of Youth and Adolescence. 12, 319-332.

Sarvela. P. D.. \& McClendon, E. J. (1983b). Early adolescent substance use/abuse in rural Northern Michigan. The Catalyst. 2,62-67.

Sarvela. P. D. Takeshita, Y.J.. \& McClendon. E. J. (1986). The influence of peers on rural Northern Michigan adolescent marijuana use. Journal of Alcohol and Drug Education. 32. 29-39.

Small. J. 1982 \% NIAAA prevention campaign target drinking and driving among youth. Alcohol Health and Research World, 7, 30.

Tolone. W. L., \& Dermott. D. (1975). Some correlates of drug use among high school youth in a rural midwestern community. International Journal of the Addictions, 10, 761-778.

L. S. Bureau of the Census, 1980.

Zucker, R. A. 19791. Developmental aspects of drinking through the young adult years. In $H$. T Blane \& M. E. Chavets (Eds.), Youth, alcohol, and social policy. New York: Plenum. 